\title{
Informatics Training for Clinicians Is More Important than Hardware and Software
}

\author{
C. Safran \\ Division of Clinical Informatics, Beth Israel Deaconess Medical Center and Harvard Medical School \\ National Center for Pubic Health Informatics, Center for Disease Control and Prevention
}

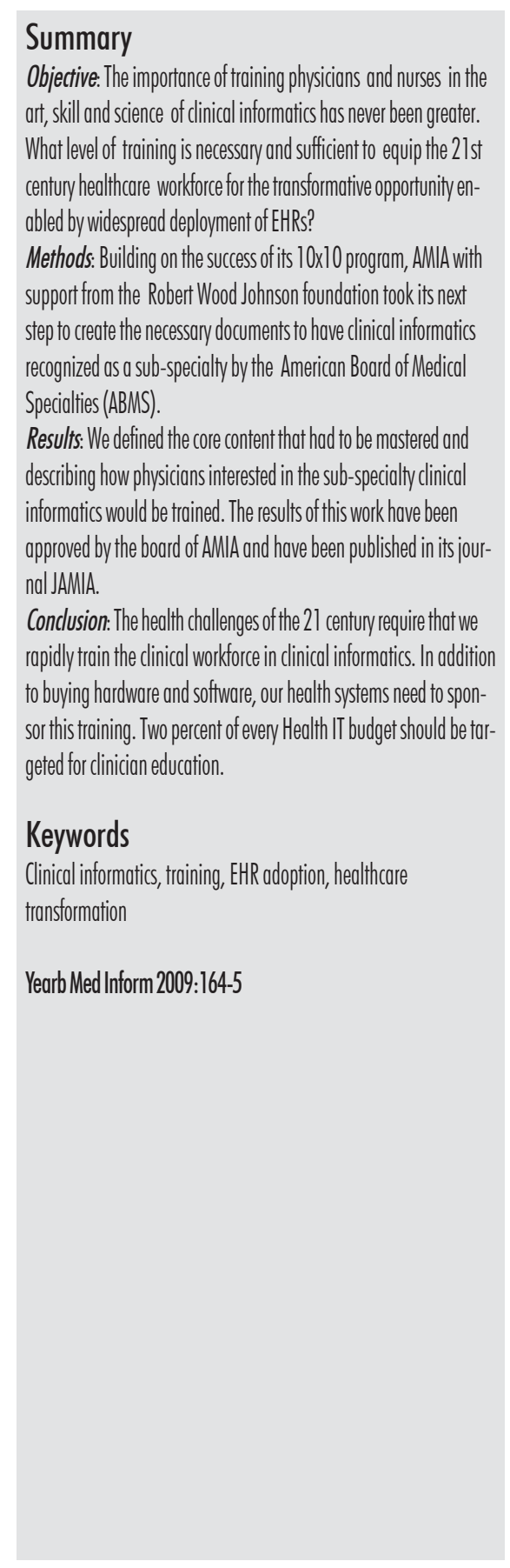

The importance of training physicians and nurses in the art, skill and science of clinical informatics has never been greater. Leadership within healthcare and government think electronic health records (EHR) will save money and improve the quality of care. Frustrated by the slow rate of adoption, President Obama has allocated \$20 billion over the next 7 years to jump-start a process that is over 2 decades old. Two billion dollars will be spent immediately for a variety of health information infrastructure projects and, starting in 2011, physicians can recover up to $\$ 18,000$ for the purchase, implementation or upgrade of certified EHR technology and up to $\$ 44,000$ for the operation, maintenance and "meaningful" use of EHRs over the ensuing 5 years.

Will just giving a physician's office an EHR solve the adoption problem? Will physicians and nurses be able to use the systems to collaborate around a patient's care? What does "meaningful" mean?

Our Division of Clinical Informatics at Beth Israel Deaconess Medical Center and Department of Medicine, Harvard Medical School will turn 40 years old in 2010 and has been developing and evolving patient-centered clinical computing systems over that entire timeframe [1]. We have had tightly integrated hospital information systems for 30 years, full EHRs for 20 years and Personal Health Records for 10 years. But at the heart of our success has been our ability to grow and train physicians and nurses interested in the use of communication and information technology to better improve patient care. In the past 2 decades, we have trained 22 fellows from 7 countries. Many more physicians, nurses and students have spent time with our Division on countless projects.

Looking around our country and the world, many of the healthcare settings where information technology has been used wisely and well have embraced informatics training as an essential component of their mission. Yet, the need for trained physicians and nurses is not keeping up with demand.

In 2004, then President Bush set a goal that $50 \%$ of physicians in the United States should be using electronic health records by 2014. A large national meeting was convened to laud this initiative with many speeches. As president of the American Medical Informatics Association at that time, I was slotted as the last speaker of the day before the Secretary of Health gave the closing remarks. As the long day deflated, and I was informed that I would have only 1 minute to respond, I whittled my well-prepared comments to only one thought. I called for the training of 6000 physicians and 6000 nurses in clinical informatics to support the implementation of EHRs and the healthcare transformation that everyone else had been talking about. I estimated the number based upon the number of hospital sites in the US. Had I chosen practice sites the number would have been almost 100 fold larger, meaning we should train everyone! I believe I was the only speaker to recognize the role of nursing in EHR implementation.

About a year after this national health IT meeting, hurricane Katrina devastated New Orleans and the gulf region. I wondered if a wet EHR was 
better or worse than a wet paper record. Of course, if a physician knew to purchase an EHR was backed-up off site...

In 2004, we graduated about 200 physicians and nurses each year from biomedical informatics programs across the US. I sent an email question to the directors of all the programs asking how many more physicians and nurses could be trained if they had more resources. All but one program said they could double their output of trainees. Oregon Health Sciences University though they could train all 12,000 using distance education. Further discussion led to the development of the very successful AMIA 10x10 program designed to train 10,000 physicians and nurses. The AMIA 10x10 program now runs in collaboration with 7 universities and has expanded to not only cover clinical informatics, but also public health informatics and bioinformatics.

The question arose, what level of training is necessary and sufficient to equip the $21^{\text {st }}$ century healthcare workforce for the transformative opportunity enabled by widespread deployment of EHRs? The 10x10 program is about 12 credit hours of graduate level work. What is a graduate of a $10 \times 10$ program qualified to do? Is $10 \times 10$ sufficient exposure or just an introduction? This is really quite a complex question because there are near term and longer term needs. Moreover, healthcare is not homogeneous nor is the workforce. The answer is that we need many levels and forms of training from our junior colleges through postdoctoral professional training.

Building on the success of its $10 \times 10$ program, AMIA with support from the Robert Wood Johnson foundation took its next step to create the necessary documents to have clinical informatics recognized as a sub-specialty by the American Board of Medical Specialties (ABMS) [2]. Such a process re- quired defining clinical informatics, defining the core content that had to be mastered[3], and describing how physicians interested in the sub-specialty clinical informatics would be trained [4]. The results of this work have been approved by the board of AMIA and have been published in its journal JAMIA. The goal of such training would be to formally train a cadre of physicians who would lead healthcare transformation using clinical informatics.

AMIA's focus on physician sub-specialty training is not meant to exclude other health professionals. In many ways, the nursing profession has been leading the way towards professional qualifications concerning informatics and others have been developing certification programs. But when a medical sup-specialty in clinical informatics is created, the healthcare informatics landscape will fundamentally change.

Clinical Informatics training programs will have to be certified by the Accreditation Council for Graduate Medical Education (ACGME). Existing training programs may have to be modified to meet training requirements including documentation that the core content is taught to each fellow. Moreover, institutions wishing to have such fellowship programs will have to commit upfront resources such as salary support for the program director to the program. Physicians will be required to take a comprehensive examination before they can be "boarded" in clinical informatics. A by-product of being recognized as a medical sub-specialty is that clinical informatics training programs will be able to compete at an intuitional level for Graduate Medical Education support (GME).

The proposed fellowship training in clinical informatics mirrors the approach we have evolved over time. Clinicians in training need some skills and some knowledge of informatics.
However, we have always recognized that large-scale systems have human as well as technical dimensions. Immersion in an environment with a challenging project coupled with substantive evaluation seems like a useful approach for an applied discipline like clinical informatics.

The health challenges of the $21^{\text {st }}$ century require that we rapidly train the clinical workforce in clinical informatics. In addition to buying hardware and software, our health systems need to sponsor this training. Two percent of every Health IT budget should be targeted for clinician education. Some of this money should be focused on the current workforce with programs like AMIA's 10x10, while some of this money should be invested in growing chief medical information officers or chief nursing information officers with formal informatics fellowship training.

\section{References}

1. Bleich HL, Beckley RF, Horowitz GL, Jackson JD, Moody ES, Franklin C, et al. Clinical Computing in a Teaching Hospital. N Engl J Med 1985;312:756-64

2. Detmer DE, Lumkin JR, Williamson JJ. Defining the Medical Subspecialty of Clinical Informatics. J Am Med Inform Assoc 2009;16:167-8.

3. Gardner RM, Overhage JM, Steen EB, Munger BS, Holmes JH, Williamson JJ, et al. Core Content for the Subspecialty of Clinical Informatics. J Am Med Inform Assoc 2009;16:153-7.

4. Safran C, Shabot MM, Munger BS, Holmes JH, Steen EB, Lumpkin JR, et al. Program Requirements for Fellowship Education in the Subspecialty of Clinical Informatics. J Am Med Inform Assoc 2009;16:158-66.

Correspondence to:

Charles Safran

Division of Clinical Informatics

Harvard Medical Faculty Physicians @ BIDMC

1330 Beacon Street - Suite 400

Brookline, MA 02446, USA

Tel: + 1 617-278-8150

E-mail: csafran@bidmc.harvard.edu 